\title{
Biosorptive Detoxification of Cosmos Red Dye by Raphinus Sativus Leaves and Citrus sinensis Peels from Water in Cost Efective and Ecofriendly Way
}

\author{
RABIA REHMAN ${ }^{*}$, MARYAM QASEEM ${ }^{1}$, LIVIU MITU* \\ ${ }^{1}$ Institute of Chemistry, University of the Punjab, Lahore-54590, Pakistan \\ ${ }^{2}$ University of Pitesti, Pitesti, Department of Nature Sciences, 1 Targu din Vale Str., 110040, Pitesti, Romania
}

\begin{abstract}
The purpose of this study was batch scale elimination of Cosmos Red dye from aqueous medium by low cost and environmentally friendly adsorbents. To study the dye removing capacity, leaves of Raphinus sativus (radish) and peels of Citrus sinensis (orange) were utilized. Two adsorption isotherms were studied to explain adsorption equilibrium. The Langmuir isotherm is compatible to adsorption data. Best adsorption capacities for Raphinus sativus and Citrus sinensis were: $3.437 \mathrm{mg} / \mathrm{g}$ and $5.844 \mathrm{mg} / \mathrm{g}$ correspondingly. Citrus sinensis peels showed more adsorption. The negative values of thermodynamic parameters $\Delta G^{o}$ for both adsorbents have shown the feasibility of this process. The results had shown that for removal of Cosmos Red dye, Citrus sinensis (orange) peels are more efficient adsorbent as compared to Raphinus sativus leaves.
\end{abstract}

Keywords: Cosmos Red dye, Citrus sinensis peels, Raphinus sativus leaves.

\section{Introduction}

Water contaminated from dyes need treatment before its discharge into fresh water reservoirs, because they are usually synthetic ones, which are not biodegradable [1]. That leads to world-wide increase in mortality rates [2]. Nearly 600 persons in Sub-continent die of polluted water associated illness daily [3]. Water is considered as polluted when anything by anthropogenic sources contaminates it. Waste water treatment is a process to convert waste water into usable form [4]. This involves the administration of human waste, solid waste, sewage and storm water controlling [5]. In a waste water treatment plant, the by products are also treated [6]. For this purpose adsorption on activated charcoal is carried out mostly for removal of dyes [7, 8]. On the basis of adsorption nature, it is usually classified as physiosorption or chemisorption. It occurs due to the electrostatic attraction [9].

Dyes are used in different types of industries i.e., textile, paper, leather, wood and food industries. To color for, hair and other biological samples various types of dyes can be used. Dyes if being exposed for long time are hazardous for both human beings and aquatic animals. The dyes make water incompatible for drinking and other uses by imparting detrimental color in it, by reducing entrance of sunlight to phytoplankton and resulting in eutrophication. They are also dangerous for mankind due to sensitivity, skin dermatitis, infection, cancer and gastrointestinal problems [10].

Cosmos Red (Figure 1) is commonly known as Congo Red, azo dye. It is water soluble, yielding a colloidal red solution. Its solubility is better in organic solvents than in aqueous medium such as ethanol. It is an anionic dye and is widely used in paper, textile, plastic and rubber industries.

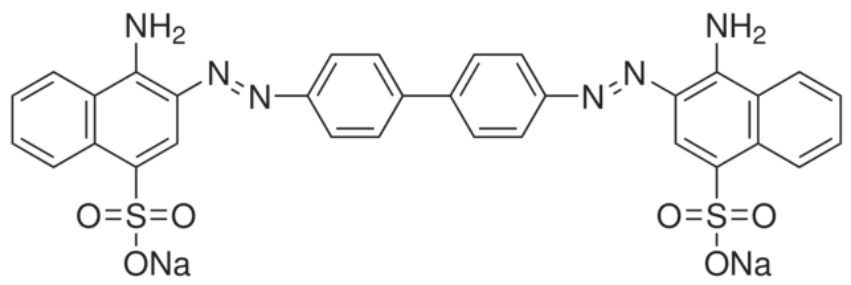

Figure 1. Structure of Cosmos Red

\footnotetext{
*email: grinorganic@yahoo.com,ktm7ro@yahoo.com
} 
In past, it was used to dye cotton but today its use has been out dated by dyes which are more resistant to light and washing but it is still used in histology to colour tissues for microscopic examination. Cosmos Red is an acid dye and it is used to test for hydrochloric acid in gastric contents [11]. It is also used in testing for amyloidosis. Cosmos Red is considered as an eye, skin and gastrointestinal nuisance. It can affect blood issues such as clotting and cause somnolence and respiratory problems [12].

In this study, Citrus sinensis peels and Raphinus sativus leaves were used for the removal of Cosmos Red. These adsorbents were not used for this dye removal before. They are abundantly available and cheap biosorbents that can be easily used with no chemical hazard in eco-friendly manner. That's why, their biosorption capacity for this dye removal was explored in this work.

The radish (Raphinus sativus) is an edible root vegetable of the Brassicaceae. Its common known in Pakistan as: radish, mooli, daikon and white radish. They are grown and eaten all over the world as a salad vegetable. The common use of radish is as cover crop in winter [13] or as a forage crop [14]. Its leaves are mostly used in salad and for decoration of cooked food in subcontinental areas [15]. Since radishes act as detoxifiers and are full of vitamin $\mathrm{C}$, folic and anthocyanins, they have been associated with the treatment of many type of cancers, especially stomach, kidney, intestinal and oral cancer.

The orange is the fruit of the citrus species in the family Rutaceae [16]. Some of the common names in which Orange is known by are Kinnow, Malta, Sangtra and Narangi orange. Oranges contain a large amount of vitamin C [17]. An orange has a thick finely textured and orange colored skin called "Orange peels". They are used in perfume and soap industry. They are safe to use on skin and aids in the treatment of skin diseases, acne and stomach ache. They contain a lot of dietary fiber. Fiber is very helpful in reducing chances of constipation.

\section{Materials and method}

\subsection{Preparation of adsorbent}

Raphinus sativus leaves and Citrus sinenses peels were taken from native markets of Lahore, washed, chopped finely, dried in sunlight and then in oven at $70-80^{\circ} \mathrm{C}$. Then it was powdered within a pin mill to the size range of 50-60 mesh (250-300 microns). In this way the samples of the simple biosorbent Raphinus sativus leaves and Citrus sinenses peels were prepared. Both these samples were stored in sealed plastic jars for further use [18].

\subsection{Characterization of adsorbent}

The prepared adsorbents were characterized by chosen physical properties (bulk density and moisture content, $p \mathrm{H}_{\mathrm{pzc}}$ ) by adopting reported methodologies and using FT-IR and SEM. The ash content Ash (\%) of the adsorbents was found out by heating at $500^{\circ} \mathrm{C}$ for $4 \mathrm{~h}$. The iodine number was determined. The functional groups containing oxygen were determined by Boehm's titration. Metal ion analysis of the adsorbent was done by taking absorbance on AAS [19-21]. The concentration of the dye in the solutions was determined by measuring the absorbance values at $520 \mathrm{~nm}$ using UV-visible spectrophotometer and comparing them with the calibration curve. Experiments were carried out in triplicate fashion, using AnalaR grade chemicals obtained from Merck and double distilled water.

\subsection{Batch adsorption study}

For this a known desired quantity of adsorbent was added to $25 \mathrm{~mL}$ of the dye solution of known concentration and known $p \mathrm{H}$ in $25 \mathrm{~mL}$ air tight volumetric flask at room temperature and solutions were then subjected to orbital shaker for proper adsorption. At different time intervals samples were withdrawn from the shaker. The adsorbents were separated from the solution through filtration and absorbance of the supernatant solution was found out by UV-visible spectrophotometer to estimate the final dye concentration. In order to find out the uptake of the dye, a whole set of experiments was performed at different time of contact $(5$ to $60 \mathrm{~min})$, temperatures $\left(20\right.$ to $80^{\circ} \mathrm{C}$ ) and $p \mathrm{H}$ (1 to 10$)$, etc 
for both adsorbent materials. The amount of Cosmos Red uptake by means of Raphinus sativus leaves as well as Citrus sinensis peels after each experiment was measured and calculated. SEM micrographs of biosorbent samples were taken using Hitachi S-3400N. 'Iodine number, is the dynamic parameter for the characterization of adsorbent. It gives the micro pore content of the adsorbent and is found out by the titrimetric determination of left over iodine by the adsorbents. The titration with $\mathrm{NaOH}$ was used to calculate the number and type of acidic sites. The number of lactonic groups was determined by titration with $\mathrm{Na}_{2} \mathrm{CO}_{3}$. The number of carboxylic groups was determined by titration with $\mathrm{NaHCO}_{3}$. The number of basic groups was determined by titration with $\mathrm{HCl}$ and results shown in (Table 1). In the present experimental work Langmuir and Freundlich isotherms were tested using their respective linear models given in equations (1) and (2) [19]:

$$
\begin{gathered}
1 / q=\left[1 /\left(q_{m} \cdot b \cdot C_{e}\right)\right]+1 / q_{m} \\
\log q=\log K_{F}+(1 / n) \log C_{e}
\end{gathered}
$$

\section{Results and discussions}

\subsection{Study of FT-IR spectra of adsorbents}

The FT-IR spectra of Raphinus sativus leaves and Citrus sinensis peels was taken to find functional groups in them, which can in turn chelate with dye species in aqueous medium. FT-IR spectra study showed that $\mathrm{O}-\mathrm{H}$ (Carboxylic acid), $\mathrm{C}-\mathrm{H}$ stretching, $\mathrm{O}-\mathrm{H}$ bond, $\mathrm{N}-\mathrm{H}$ stretching, $\mathrm{C}=\mathrm{C}$ aromatic bond, C-O and C-F functional groups are present on the surface of biosorbent as shown in (Figures 2 and 3). From FT-IR of Raphinus sativus leaves before and after the adsorption of Cosmos Red dye it was indicated that there was a change in wave number $3250-3300 \mathrm{~cm}^{-1}, 1588-1598 \mathrm{~cm}^{-1}$, $1407-1421 \mathrm{~cm}^{-1}, 1144-1238 \mathrm{~cm}^{-1}$ and $1011-1009 \mathrm{~cm}^{-1}$ of $\mathrm{O}-\mathrm{H}$ bond, $\mathrm{N}-\mathrm{H}$ stretching, $\mathrm{C}=\mathrm{C}$ bond, C-O and $\mathrm{C}-\mathrm{F}$ bond, respectively. The increase in the wave number of $\mathrm{O}-\mathrm{H}$ bond, $\mathrm{N}-\mathrm{H}$ stretching, $\mathrm{C}=\mathrm{C}$ bond, $\mathrm{C}-\mathrm{O}$ bond and decrease in the wave number of $\mathrm{C}-\mathrm{F}$ bond indicated their involvement in ionic interaction for biosorptive removal of Cosmos Red dye by Raphinus sativus leaves.

From FT-IR of Citrus sinensis peels before and after the adsorption of Cosmos Red dye it was indicated that there was a change in wave number $1737-1735 \mathrm{~cm}^{-1}, 1371-1365 \mathrm{~cm}^{-1}, 888-817 \mathrm{~cm}^{-1}$ and $1013-1010 \mathrm{~cm}^{-1}$ of $\mathrm{C}=\mathrm{O}$ stretching, $\mathrm{S}=\mathrm{O}$ sulfates, $\mathrm{C}-\mathrm{H}$ bond (aromatic) and $\mathrm{C}-\mathrm{F}$ bond, respectively. The decrease in the wave number of $\mathrm{C}=\mathrm{O}$ stretching, $\mathrm{S}=\mathrm{O}$ sulfates, $\mathrm{C}-\mathrm{H}$ bond (aromatic) and $\mathrm{C}-\mathrm{F}$ bond indicated their involvement in ionic interaction for biosorptive removal of Cosmos Red dye by Citrus sinensis peels.

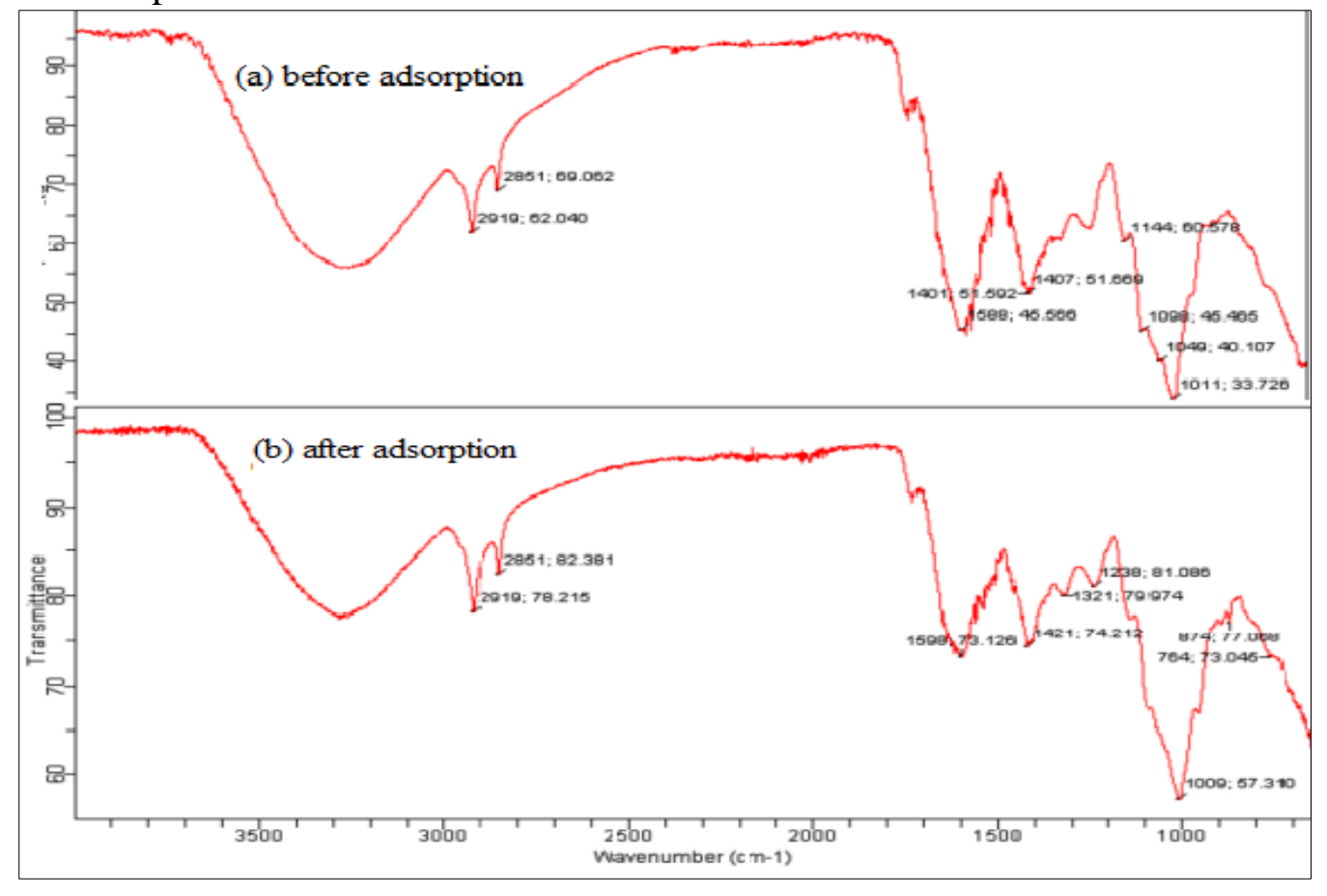

Figure 2. FT-IR spectra of Raphinus sativus leaves 


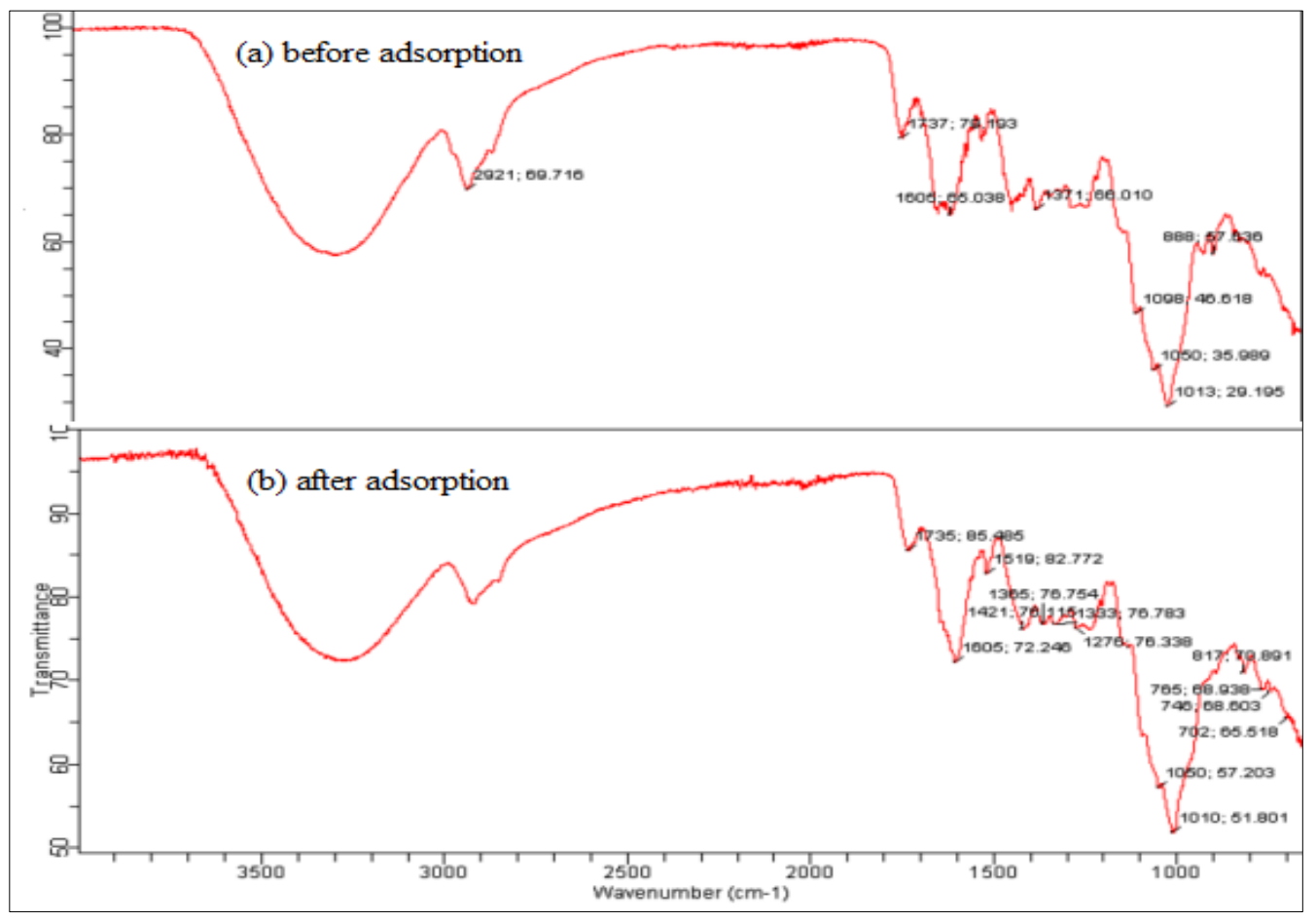

Figure 3. FT-IR spectra of Citrus sinensis peels

\subsection{Study of SEM micrographs of adsorbents}

SEM micrographs were given in (Figures 4 and 5, magnification $500 \mathrm{KX}$ ). They are showing that Raphinus sativus leaves and Citrus sinensis peels have rough cavities and fibrulose structure, which was more compactly arranged after adsorption of dye molecules in cavities. It indicated physiosorptive removal of Cosmos Red dye.

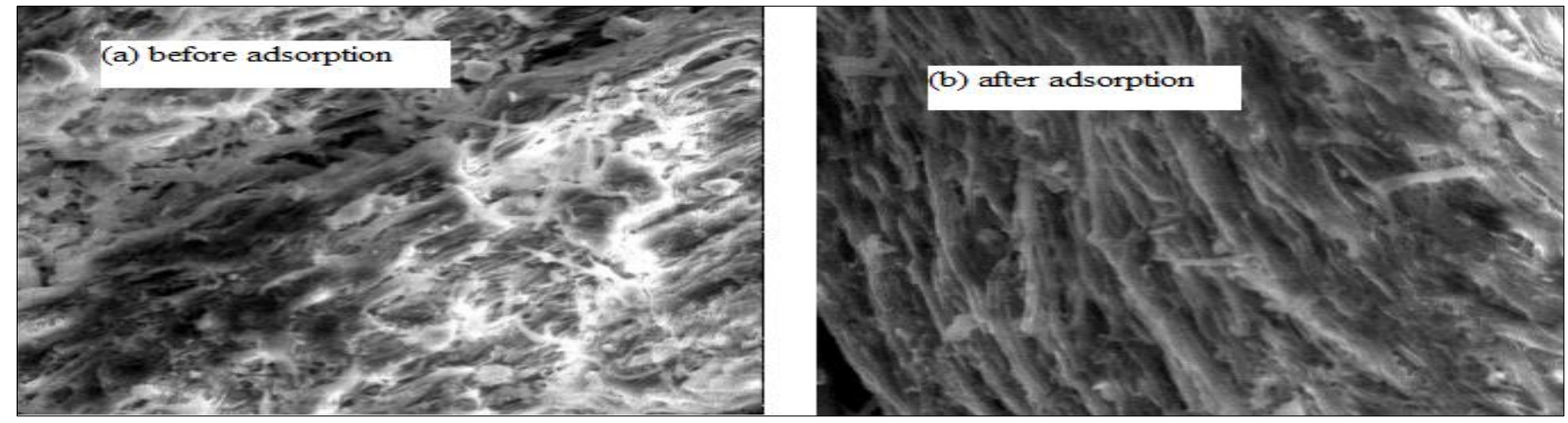

Figure 4. SEM images of Raphinus sativus leaves
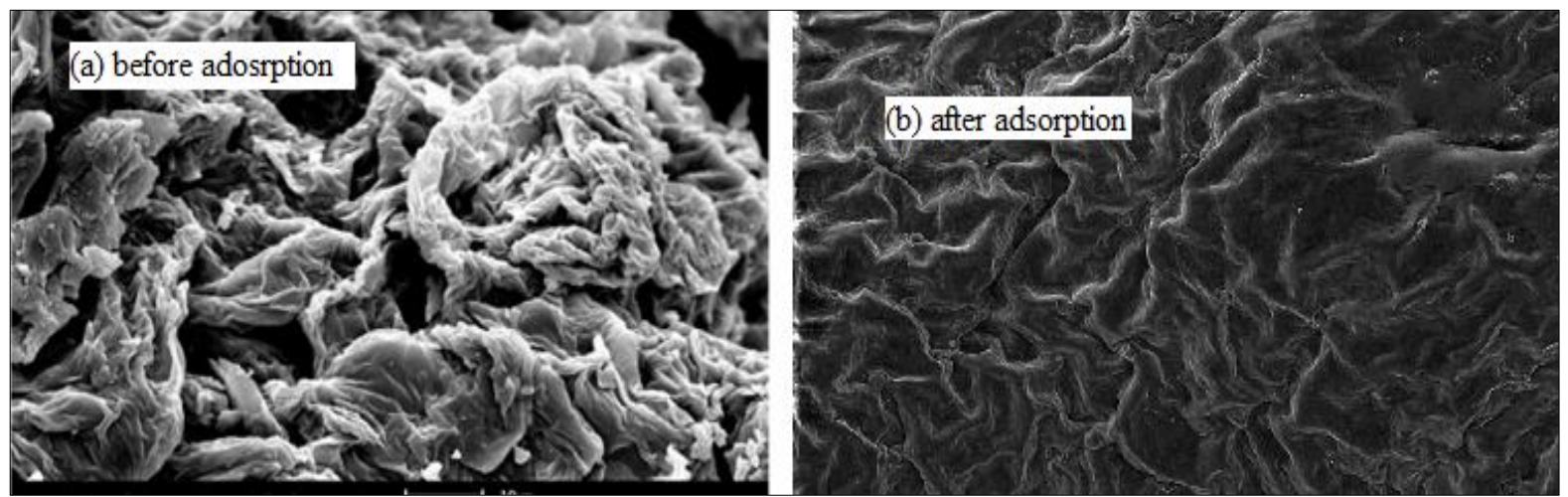

Figure 5. SEM images of Citrus sinensis peels 


\subsection{Determination of $p H_{p z c}$}

For determination of specific type of functional groups on the surface of adsorbent its $p \mathrm{H}$ is checked. The $p \mathrm{H}$ of Raphinus sativus leaves was 7, determined from the graph which indicated its neutral nature (Figure 6).

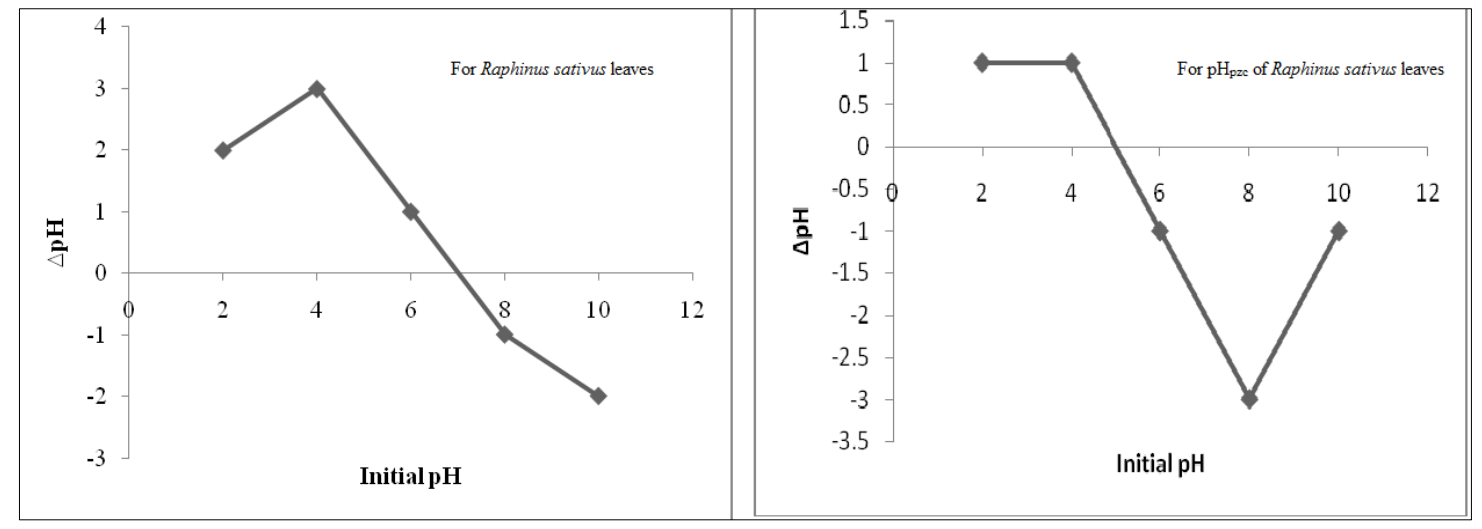

Figure 6. $\mathrm{pH}_{\mathrm{pzc}}$ of Raphinus sativus leaves and Citrus sinensis peels

The $p \mathrm{H}$ of the Citrus sinensis peels was 5 (Figure 6), which indicated its acidic nature. In low $p \mathrm{H}$ range of dye solution, protonation of these acidic functional groups occurred more, which is helpful in removal of Cosmos Red dye. Moreover in acidic media, the biosorbing material surface become more ionized. At low $p \mathrm{H}$, the anion adsorption was favorable on adsorbents. Moreover in case of Citrus sinensis (\%) age adsorption value is more in acidic medium as the adsorbent become ionized that in acidic media.

\subsection{Physiochemical characterization of adsorbents}

The analysis of biosorbent as given in (Table 1) showed a comparatively little amount of bulk density, ash content and volatile matter content showing that these biosorbents can be outstanding materials for adsorption studies. The porosity improves dye removing capacity of these materials as it claims pores number present per unit of adsorbent. The low amount of moisture content of above mentioned adsorbents showed small density of particles. Therefore Raphinus sativus leaves and Citrus sinensis peels can be used as better adsorbents. Raphinus sativus leaves had less ash content and more volatile matter than Citrus sinensis peels indicating that it can be easily prepared as biosorbent for industrial use as compared to activated charcoal, where a huge amount of fuel is required for its preparation.

Table 1. Physiochemical analysis of Raphinus sativus leaves and Citrus sinensis peels

\begin{tabular}{|c|c|c|c|}
\hline \multicolumn{2}{|c|}{ Characteristics } & Raphinus sativus leaves & Citrus sinensis peels \\
\hline \multicolumn{2}{|c|}{ Bulk density $\mathrm{P}_{\text {wet }}$} & 0.1625 & 0.105 \\
\hline \multicolumn{2}{|c|}{ Porosity (\%) } & 0.9092 & 0.9092 \\
\hline \multicolumn{2}{|c|}{ Moisture (\%) } & 12.74 & 17.47 \\
\hline \multicolumn{2}{|c|}{ Ash $(\%)$} & 90 & 99 \\
\hline \multicolumn{2}{|c|}{ Volatile matter (\%) } & 10 & 1 \\
\hline \multicolumn{2}{|c|}{ Iodine number $(\mathrm{mg} / \mathrm{g})$} & 11.280 & 5.640 \\
\hline \multirow{4}{*}{$\begin{array}{l}\text { Elemental content } \\
(\%)\end{array}$} & $\mathrm{Na}^{+}$ & 0.603 & 0 \\
\hline & $\mathrm{K}^{+}$ & 6.761 & 0.893 \\
\hline & $\mathrm{Ca}^{+2}$ & 1.236 & 0.076 \\
\hline & $\mathrm{Mg}^{+2}$ & 0.178 & 0 \\
\hline \multirow{4}{*}{$\begin{array}{l}\text { Functional group } \\
\qquad(\mathrm{mmol} / \mathrm{g})\end{array}$} & Basic group & 0.07 & 0.10 \\
\hline & Phenolic & 0.05 & 0.01 \\
\hline & Lactonic & 0.11 & 0.08 \\
\hline & $\begin{array}{l}\text { Carboxylic } \\
\text { (acidic } \\
\text { functions) }\end{array}$ & 0.128 & 0.08 \\
\hline
\end{tabular}


Raphinus sativus leaves greater Iodine number indicate that it has more unsaturated functional groups that can chelate more dye molecules from water. Its greater acidic contents indicate that it can adsorb more protonic dyes as compared to anionic dyes. Whereas Citrus sinensis peels can adsorb more anionic dyes due to more basic functional groups. Results of adsorption studies also indicate same trend.

\subsection{Optimization of operational conditions}

All conditions were optimized one by one and results are graphically summarized in (Figure 7).

(a) Adsorbent dose effect

The comparative study of adsorption of Cosmos Red on Citrus sinensis peels and Raphinus sativus leaves was studied and presented graphically in (Figure 7). It was indicated that the adsorption of dye increase with increasing adsorbent dose for peels of Citrus sinensis because it provides increase in pores available for the adsorption and also the surface area got increased. Hence, the enhancement in the adsorption efficiency was seen with the increment in the adsorbent dose [20] until $0.2-0.8 \mathrm{~g}$, while same trend is in the case of Raphinus sativus leaves [20]. For Raphinus sativus leaves biosorptive removal of Cosmos Red dye was $74.09 \%$ at $0.2 \mathrm{~g}$ and for Citrus sinensis peels it was $92.56 \%$ at $0.6 \mathrm{~g}$ dose.

\section{(b) Effect of dye solution $p \mathrm{H}$}

It is a significant parameter for removal of dye and it displays the acidic or basic nature of dye. In the present study, biosorptive removal of Cosmos Red dye was slowly reduced from $82.10 \%$ to 54.39 $\%$ at $p \mathrm{H}=1.0-3.0$ for Citrus sinensis (Cs) peels as clear from (Figure 7). Then gradually the adsorption increases and maximum percentage removal was observed at $p \mathrm{H} 6$ i.e., $88.35 \%$, whereas at $p \mathrm{H}=1.0$ 6.0 the percentage removal of Cosmos Red for Raphinus sativus (Rs) leaves was steadily decreased from $97.86 \%$ to $53.04 \%$. Then at $p \mathrm{H} 7$ a sharp increase was observed where percentage removal was $87.62 \%$, it then decreased from

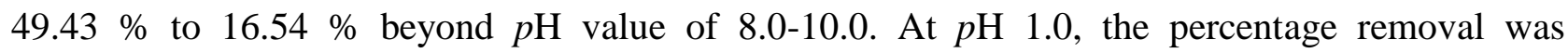
maximum i.e., $97.86 \%$. Thus, it had shown that for both adsorbents, biosorption capacity was more in acidic $p \mathrm{H}$, due to the fact that at higher $p \mathrm{H}$ range, precipitative removal of dye occurred more rather than its biosorptive removal.

\section{(c) Effect of contact time}

The effect of time on adsorption of Cosmos Red on Citrus sinensis peels and Raphinus sativus leaves was studied and shown in (Figure 7). Maximum removal of dye occurred within 35.0 min using Raphinus sativus leaves i.e., $81.96 \%$ and in 60 min using Citrus sinensis peels i.e., 97.26\%. This is due to saturation of binding sites the equilibrium established so far between adsorbent and dye. Initially dye molecules attached with surface, later on mass transfer to inner layers of biosorbing matter occurred slowly. The effect of contact time on the percentage removal of Cosmos Red dye increases rapidly with time. This indicates that the reaction towards the equilibrium between the dye and adsorbent is favored by longer contact time.

\section{(d) Effect of temperature}

Along with other optimization factors of adsorption study, temperature is also an important parameter. As indicated from (Figure 7) that this process is better at slightly moderate temperatures. It was found that for Citrus sinensis peels, removal of dye decreased with rising temperature. It means rise in temperature reduces their surface active sites. Maximum removal occurred at $20^{\circ} \mathrm{C}$ i.e., 91.32 $\%$. For Raphinus sativus leaves, with increase in temperature at $20.0-50.0^{\circ} \mathrm{C}$ there is a decrease in removing ability of adsorbent for Cosmos Red and was maximum at $60^{\circ} \mathrm{C}$ i.e., $64.64 \%$. It was seen that for Raphinus sativus leaves, as the temperature was increased, the dye removal was increased. The 
increase in temperature increases the mobility of ions, along with swelling in biomass surface, resulting in more exposure of active binding sites. So, it helps in quicker adsorption [20].

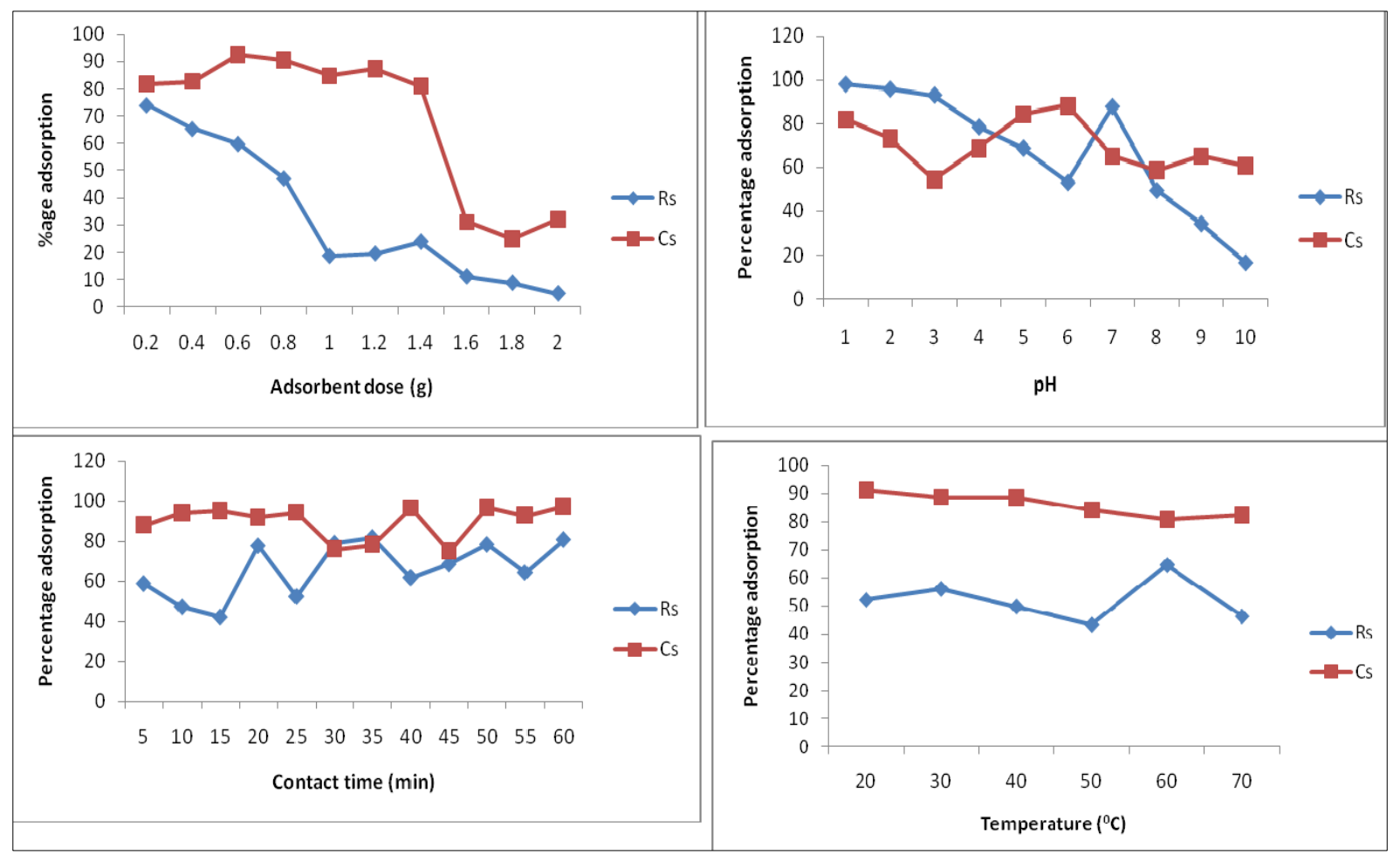

Figure 7. Comparative study of operational conditions effect on Cosmos Red adsorption

\subsection{Isothermal modeling}

To describe adsorption capacity which eases assessment of the viability of adsorption process for a given application, for preliminary determination of adsorbent dosage requirements and for choice of the most suitable adsorbent experimental isotherm is useful. To represent the data of adsorption from solution, the Langmuir (1916) and Freundlich (1906) isotherms are most commonly used using optimized conditions of adsorbent for Cosmos Red [22, 23]. Resultant isothermal parameter constants are presented in (Table 2). Langmuir model favors adsorption of dye molecules in monolayer fashion on biosorbing material without interference due to homogeneity of active binding sites on adsorbent. In this case, Langmuir isotherm was followed more as clear from (Table 2). Freundlich isotherm favors physiosorption and heterogeneous multilayer adsorption sites availability [24].

The results have exposed that Citrus sinensis peels had more potential for removal of Cosmos Red by chemisorption mode with maximum removing capability $5.844 \mathrm{mg} / \mathrm{g}$; Thermodynamic feasibility $\Delta \mathrm{G}^{\mathrm{o}}$ was $-5.754 \mathrm{KJ} / \mathrm{mol}$, which means this process was exothermic and unprompted adsorption occurred by Citrus sinensis peels, while in case of Raphinus sativus leaves, physiosorption capacity was more with maximum removing capability $K_{F}=30.317 \mathrm{mg}^{1-(1 / n)} \cdot \mathrm{L}^{1 / \mathrm{n}} \cdot \mathrm{g}^{-1}$. Both biomass sorption capacities were compared with reported biosorbing materials obtained from agricultural sources for acidic dyes in (Table 3), which is also indicating their promising behavior. Greater $\mathrm{R}^{2}$ values for Langmuir model rather than Freundlich isotherm means greater biosorptive removal of dye occurred due to homogenous binding sites availability on Citrus sinensis peels and Raphinus sativus leaves surface followed by slower physiosorption in deeper heterogeneous binding sites. 
Table 2. Isothermal studies results

\begin{tabular}{|c|c|c|c|c|c|c|}
\hline \multicolumn{7}{|c|}{ (a) Langmuir model } \\
\hline Biomass & Slope & Intercept & $\overline{\mathbf{R}^{2}}$ & $q_{m}\left(m \cdot g^{-1}\right)$ & $\begin{array}{c}\mathbf{b} \\
(\text { L.mg } \\
\end{array}$ & $\begin{array}{c}\Delta \mathbf{G}^{\mathbf{0}} \\
\left(\mathrm{KJ}_{\mathrm{J}} \mathrm{mol}^{-1}\right)\end{array}$ \\
\hline Raphanus sativus leaves & 6.617 & 0.290 & 0.908 & 3.437 & 0.043 & -7.744 \\
\hline Citrus sinensis peels & 1.744 & 0.171 & 0.96 & 5.844 & 0.098 & -5.754 \\
\hline \multicolumn{7}{|c|}{ (b) Freundlich model } \\
\hline Biomass & Slope & Intercept & $\mathbf{R}^{2}$ & $\begin{array}{c}\mathbf{K}_{\mathbf{f}} \\
{\left[\mathrm{mg}^{1-(1 / \mathbf{n})} \mathbf{L}^{1 / \mathbf{n}} \mathbf{g}^{-1}\right]}\end{array}$ & \multicolumn{2}{|c|}{$\mathbf{n}$} \\
\hline Raphanus sativus leaves & 1.970 & 1.481 & 0.898 & 30.317 & \multicolumn{2}{|c|}{0.507} \\
\hline Citrus sinensis peels & 0.597 & 0.146 & 0.918 & 1.400 & \multicolumn{2}{|c|}{1.673} \\
\hline
\end{tabular}

Table 3. Comparison of maximum sorption capacity with reported adsorbents

\begin{tabular}{|c|c|c|}
\hline Adsorbent & $q_{\mathrm{m}}(\mathrm{mg} / \mathrm{g})$ & References \\
\hline Solanum tuberosum peels & 6.993 & \multirow[t]{2}{*}[25]{} \\
\hline Pisum sativum peels & 16.393 & \\
\hline Raphanus sativus peels & 0.069 & \multirow{3}{*}[15]{} \\
\hline Grewia asiatica leaves & 0.566 & \\
\hline Activated Charcoal & 0.929 & \\
\hline Wheat bran & 22.73 & \multirow[t]{2}{*}[26]{} \\
\hline Rice bran & 14.63 & \\
\hline Phoenix dactylifera seeds & 61.72 & [27] \\
\hline Pineapple plant stem & 11.96 & {$[28]$} \\
\hline Raphanus sativus & 3.437 & \multirow[t]{2}{*}{ Current work } \\
\hline Citrus sinensis & 5.844 & \\
\hline
\end{tabular}

\section{Conclusions}

So, Citrus sinensis peels and Raphinus sativus leaves used here as biosorbents for the removal of man-made dye for example Cosmos Red. Functional groups were characterized by FT-IR and Boehm's titration and morphological aspects were observed by SEM micrographs. Moreover, using Langmuir and Freundlich isothermal modeling [29,30], maximum dye removal ' $\mathrm{q}_{\mathrm{m}}$ ' was $3.437 \mathrm{mg} / \mathrm{g}$; $5.844 \mathrm{mg} / \mathrm{g} ; \mathrm{K}_{\mathrm{f}}=30.317 ; 1.4 ; \Delta \mathrm{G}^{\mathrm{o}}=-7.744 \mathrm{~kJ} / \mathrm{mol} ;-5.754 \mathrm{~kJ} / \mathrm{mol}$ and $\mathrm{n}=0.507 ; 1.673$ were found for Raphinus sativus leaves and Citrus sinensis peels correspondingly, indicating chemisorption along with physiosorption both plays important role in Cosmos Red dye removal. Langmuir's isotherm was found to be more compatible.

\section{List of Abbreviations}

AAS: Atomic absorption spectrometer

FT-IR: Fourier Transform Infra-Red

SEM: Scanning electron microscope

Cs: $\quad$ Citrus sinensis peels

Rs: $\quad$ Raphinus sativus leaves

\section{References}

1.AKSU, Z., Process Biochem., 40, 2005, p. 997

2.GUPTA, V.K., J.Env.Manage., 90, 2009, p. 2313

3.FORGACES, E., CSERHATI, T., OROS, G., Env.Int., 30, 2004, p. 953 
4.HAMMER, J., Water and waste water technology, John Wiley \& Sons, New York,1975, p. 300 5.KEMMER, N., The nalco water handbook, McGraw-Hill Book Company, New York, 1979, p. 547 6.TCHOBANOGLOUS, G., BURTON, F.L., STENSEL, H.D., Chapter 14: Treatment, reuse and disposal of solids and biosolids, Waste water engineering: treatment and reuse, 4th Ed., Metcalf \& Eddy, Inc., McGraw Hill, USA, 2003, p. 987

7.KAYSER, H., Annalen der Physik, 248, 1881, p. 526

8.ALLEN, S.J., KOUMANOVA, B., J.Univ.Chem.Tech.Metall., 40, 2005, p. 175

9.FERRARI, L., KAUFMANN, J., WINNEFELD, F., PLANK, J., J.Coll.Int.Sci., 347, 2010, p. 15

10.REHMAN, S., MUNIR, M., ASHFAQ, M., RASHID, N., NAZAR, F., DANISH, M., HAN, J.I., Chem.Eng.J., 228, 2013, p. 54

11.STEJSKAL, J., Chem Papers, 74, 2020, p.1.

12.YANG, Y., WANG, B., LI, Z., JIA, X., ZHOU, Q., ZHAO, Y., Bioresource Tech., 102, 2011, p. 828

13.SENTHIKUMAAR, S., BHARATHIB, S., NITHYANANDHIB, D., SUBBURAMB, V., Bioresource Tech., 75, 2000, p. 163

14.AHMED, S., CHUGHTAI, S., KEANE, M.A., Sep.Purif.Tech., 13, 1998, p. 57

15.REHMAN, R., ABBAS, A., MURTAZA, S., MAHMUD, T., ZAMAN, W., SALMAN, M., SHAFIQUE, U., J.Chem.Soc.Pak., 34, 2012, p. 112

16.NICOLOSI, E., DENG, Z.N., GENTILE, A., LA MALFA, S., CONTINELLA, G.,

17.TRIBULATO, E., Theoret.App.Genet., 100, 2000, p. 1155

18.ROMERO, M.A., J.Chromat.Sci., 30, 1992, p. 433

19.KIERNAN, J.A., Biotech.Histochem., 76, 2001, p. 261

20.REIJENGA, J., HOOF, A., LOON, A., TEUNISSEN, B., Anal.Chem.Insights., 8, 2013, p. 53

21.ABBAS, A., MURTAZA, S., MUNIR, M., ZAHID, T., ABBAS, N., Amer.Eurasian J.Agric.\& Environ.Sci., 10, 2011, p. 802

22.AHMAD, R., MONDAL, P.K., Sep.Sci.Tech., 44, 2009, p. 1638

23.NAGDA, G.K., GHOLE, V.S., Iran.J.Environ.Health.Sci.Eng., 6, 2009, p. 195

24.AHMAD, R., KUMAR, R., Appl.Surf.Sci., 257, 2010, p. 1628

25.REHMAN, R., MANZOOR, I., MITU, L., Bull.Chem.Soc.Ethiopia, 32, 2018, p. 213

26.WANG, X.S., CHEN, J.P., Sep.Sci.Tech., 44, 2009, p. 1452

27.PATHANIA, D., SHARMA, A., SIDDIQI, Z.M., J.Mol.Liquids, 219, 2016, p. 359

28.CHAN, S.L., TAN, Y.P., ABDULLAH, A.H., ONG, S.T., J.Taiwan Inst.Chem.Eng., 61, 2016, p. 306

29.MURESAN, E. I., ZAHARIA, C., MURESAN, A., CEREMPEI, A., RADU, C. D., \& SANDU, I. G, Rev. Chim., 67, 2016, p.1232

30.BACIOIU, I. G., STOICA, L., CONSTANTIN, C., STANESCU, A. M, Rev. Chim, 67, 2016, p.2391

Manuscript received: 24.01 .2020 